\title{
Optimal Production Decisions of Green Supply Chain Under Random Demand in Production Manufacturing
}

\author{
Yi Wang ${ }^{1 *}$, Jian $\mathrm{Hu}^{1}$, Mengxue Du ${ }^{1}$, Jianhua Zhang ${ }^{2}$ \\ ${ }^{1}$ College of Science, Tianjin University of Commerce, Tianjin300134, China \\ ${ }^{2}$ School of Economics and Management, Northeast Petroleum University, Heilongjiang 163318, China \\ *Corresponding Author.
}

\begin{abstract}
To investigate supply chain's performance in production manufacturing industry, we establish a green one under random demand containing two members. In the channel, production quantity, wholesale price, and green-level are decided by the manufacturer. Retail price is decided by the retailer. It shows how the parameters, such as the market potential, consumers' preference for green products, production cost and the green investment parameter, influence the performance of the production, pricing decision, whole channel's profit. We find that: (1) When the two members work as a team, green-level will increase, and this will also promote sustainable development of green production; (2) In the face of random demand, improvements in the manufacturer's green production technology, increased promotion of green products by the retailer, and enhanced green preferences of consumers are all conductive to improve channel's total profit.
\end{abstract}

Keywords: Green supply chain, Random demand, Newsvendor model, Production manufacturing

\section{Introduction}

Nowadays, environmental protection regulations are becoming increasingly strict. With the rise of public awareness in sustainable development, green products are more attractive to consumers than ever before. So considering the resource consumption and environmental impact, green supply chains are getting more attention ${ }^{[1]}$. In fact, many enterprises have benefited from green supply chain management and have raised their profits as well as corporate reputations ${ }^{[2]}$. In addition, enterprise operation will inevitably be affected by the randomness. Therefore, how to avoid the risks caused by the randomness is a cutting edge. In our manuscript, we focus on the management of green products under random demand.

In 1996, green supply chain comes the first time in the "Environmentally Responsible Manufacturing (ERP)" project. Green supply chain(also known as ECSC), comes out of theory in sustainable development and basic principles of supply chain management ${ }^{[3]}$. It aims to realize optimal allocation of resources and to improve social welfare and compatibility with the environment. It is a system composed of suppliers, manufacturers, retailers, consumers, environment, regulations and cultures. It is a cross-subject of logistics, information, capital, knowledge, etc. ${ }^{[4]}$. Green product supply chain management is significant for enterprises to obtain both domestic and international markets, and is important to raise competitiveness and sustainable development of companies. Adidas, has also made a lot of efforts to reduce the environmental impact. The goal is to minimize the environmental impact from harmful raw materials and package wastes in manufacturing. In fact, many enterprises such as IBM, Xerox and HP, have already made great efforts to lower environment impact and to higher management level. Another clothing brand, Patagonia, the top high-end outdoor brand, has been making great efforts to green its products in its process ${ }^{[5]}$. Its environmental actions are still highly evaluated by people today. In 2008, Patagonia started a team to track the production and sales process of the products, they found a raw material which is harmful to human beings. Therefore, the company immediately chose new materials, redesigned its products, changed its manufacturing processes, and provided consumers with more environmentally friendly products and better services. In April 2011, Haier held a recruitment campaign for China's green talents "Green

ISSN: 0010-8189

(C) CONVERTER 2020

www.converter-magazine.info 
Space, Enjoy Life" to enable consumers to feel the charm of a green, energy-saving and environment-friendly life. Haier has started to focus on displaying the world-class products of green and energy-saving household applicants. They said that it will take responsibility in leading the corporate green manufacturing, and introduce more green and environment-friendly products to the global market (Dai, 2011 ${ }^{[6]}$ ). Then, at the 2014 World Expo, Gree, Midea and some other companies also showed their latest energy-saving products to consumers. In this condition, enterprises must develop green products to obtain favorable advantages in market.

Not only manufacturers, retailers also show great enthusiasm in environmental protection. For example, the biggest player in retailing field, Walmart, said it would take full responsibility for the environmental impacts of its products from then on. Subsequently, Walmart carried out several measures in the process of greening their supply chains ${ }^{[5]}$. Walmart has also provided lots of support to suppliers, taking advantage of its strong relationship with the government environmental department. Best Buy is also an insightful retailer in electronic field. It has changed the traditional sales mode of commission system and sales only products certified by Energy Star. People's life is improving every day and the awareness in protecting environment is raised continuously. Consumers are more likely to use products which are environment harmless, such as environmental protection household appliances, electric vehicles, ceramic tiles, ecological houses, solar energy, etc. A survey covering 3 years showed that consumers who prefer green products in Europe have increased $31 \%{ }^{[7]}$. With the requirement of environmental protection, how should the channel members of green supply chains interact to improve their performance in providing more green products becomes popular. For consumers, their chosen of products has brought great uncertainty to the production and operation of the enterprise. In existing results, there are few relevant studies on green supply chain management. In this manuscript, we study green newsvendor supply chain model under random demand.

Section II shows the related literature, and provides notations and assumptions in our demand model. Section III describes supply chain model with two members. Numerical experiments are analyzed in Section IV and conclusions are presented in Section V. All the proofs present in Section V.

\section{Literature Review}

\subsection{Random demand}

Designment of green supply chain remains relatively active. In design stage, optimal decisions is obtained to balance whole channel's cost and environmental impact ${ }^{[8]}$. Ameknassi et al. ${ }^{[9]}$ developed a program chain model to coordinate those relative members. To level the conflicts between our environment and finance problem, a new model was designed ${ }^{[10]}$. Waltho et al. ${ }^{[11]}$ reviewed designment of different supply chain models together with searching methods.

Random demand model and supply chain structure are two key factors infecting the performance of green supply chain. Randomness always has two forms: one is demand side fluctuations and another is supply side disruptions. How to mitigate risks formed from randomness is the main task in supply chain management. Ghelichi et al. ${ }^{[12]}$ unveiled a random demand modelespecially for a plant named Jatropha. Bhakti et al. ${ }^{[13]}$ considered an agri-food supply chains with random demands. Yu and Zhang ${ }^{[14]}$ proposed a new method to faster operation process on optimal price. Islam et al. ${ }^{[15]}$ developed a supply chain containing three members under random supply. Xin et al. ${ }^{[16]}$ studied optimal decisions of a random supply chain model. For more results on supply chain's randomness, we prefer readers to Badi and Murtagh ${ }^{[17]}$.

As early as 2006, Tsoulfas and Pappis ${ }^{[18]}$ placed the green product design principle as the first principle of the six environmental principles. Even so, green product design has not yet attracted widespread attention from scholars. Most scholars concentrating on the relationship between the government and the supplier, but fewer delved into the internal relationships of green supply chain systems-the competition or partnership between upstream and downstream members. In our paper, we take insight into internal structure of green supply chain under random demand: 
1. A supply chain with centralized and decentralized structure is studied, and the equilibrium solutions are obtained which provides an optimal decision to the companies.

2. The influence of various parameters on main variables and total channel's performance is analyzed, providing a theoretical basis for green production practitioners.

Compared to existing literature, method used in our manuscript is an extension comparing withthe adopted models before. For instance, Zhu et al. ${ }^{[19]}$ proposed a linear demand model in green products, and we extend the model into the random case. Moreover, comparing to the model of Wang et al. ${ }^{[20]}$, we add the green-level choice as a linear term in the demand model.

\subsection{Newsvendor Model}

In our paper, a supply chain containing two members is investigated under linear random demand model with the centralized and decentralized structure. The linear demand model is favored by experts and scholars ${ }^{[19]}$. In centralized channel, both two members performs like a total unit in deciding optimal decisions. In decentralized channel, two members are competitive in maximizing their own profit, paying no attention to the other one's profit. Therefore, these two members will reach an equilibrium state by bargaining. By Li et al. ${ }^{[21]}$, we have the following assumptions and descriptions. Figure 1 and Table 1 respectively present our model's structure and notations. We will add a superscript "*” on any notations to represent as its optimal solution. Besides, a subscript "c" denotes the performance in a centralized channel, and " $\mathrm{d}$ " denotes the performance in decentralized one.
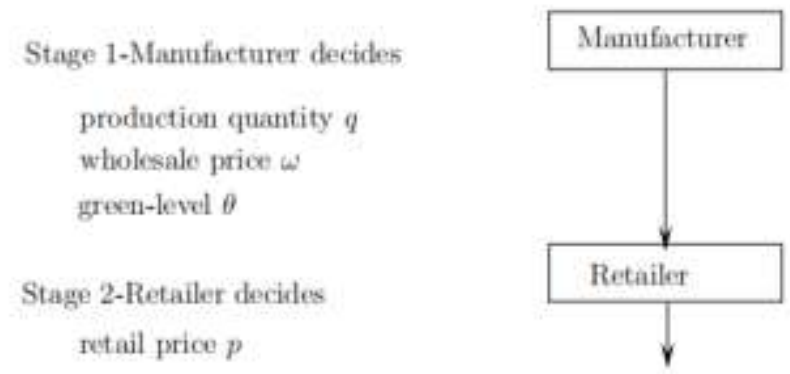

Figure 1: Two stage structure

Table 1 Notations

\begin{tabular}{|c|l|}
\hline Notation & \multicolumn{1}{|c|}{ Explanation } \\
\hline$p$ & retail price \\
\hline$\theta$ & green-level \\
\hline$\varepsilon$ & random variable $\varepsilon \in[A, B]$ \\
\hline$D(p, \theta, \varepsilon)$ & the price and green-level sensitive linear random demand \\
\hline$I$ & green investment parameter \\
\hline$f(\cdot)$ & probability density function \\
\hline$F(\cdot)$ & cumulative distribution function, with $\bar{F}(\cdot)=1-F(\cdot)$ \\
\hline$h(x)$ & failure rate functio, with $h(x)=\frac{f(x)}{1-F(x)}$ \\
\hline$c$ & the cost of producing green products \\
\hline$q$ & production quantity of the manufacturer \\
\hline
\end{tabular}

ISSN: 0010-8189 


\begin{tabular}{|c|l|}
\hline$\omega$ & wholesale price \\
\hline $\boldsymbol{z}$ & inventory factor \\
\hline$\Pi_{C}$ & whole channel's profit in centralized channel \\
\hline$\Pi_{d, M}$ & manufacturer's profit in decentralized channel \\
\hline$\Pi_{d, R}$ & retailer's profit in decentralized channel \\
\hline
\end{tabular}

We assume that market demand has linear structure as follows:

$$
D(p, \theta, \varepsilon)=y(p, \theta)+\varepsilon=a-p+b \theta
$$

By Petruzzi and Dada ${ }^{[22]}$, we follow the definition of inventory factor as $z=q-y(p, \theta)$, and $E[\min \{D, q\}]=q-\Lambda(\mathrm{z})$. For more information, one can see Choi and Cheng ${ }^{[23]}$.

\section{Models of two structures}

\subsection{Research on Centralized Channel}

Members in the centralized supply chain make decisions together. The whole channel's profit is

$$
\Pi_{c}(p, q, \theta)=p E[\min [D, q]]-c q-I \theta^{2}=p(q-\Lambda(z))-c q-I \theta^{2}
$$

By substituting $z=q-y(p, \theta)$ into Eq. (1), we rewrite the channel's profit function as follows:

$$
\Pi_{c}(p, z, \theta)=(p-c)(z+a-p+b \theta)-p \Lambda(z)-I \theta^{2}
$$

By first-order condition, the optimal decisions of Eq. (2) are obtained.

Theorem 1: In conditions $4 I-b^{2}>0$ and $h(z)>\frac{F(z) \bar{F}(z)}{a-c+z-\Lambda(z)}$, optimal decisions are as follows:

$$
\begin{aligned}
& p_{c}^{*}(z)=\frac{2 I(a-c+z-\Lambda(z))}{4 I-b^{2}}+c \\
& \theta_{c}^{*}(z)=\frac{b(a-c+z-\Lambda(z))}{4 I-b^{2}}
\end{aligned}
$$

and the optimal stocking factor $z=z_{c}^{*}$ is decided as

$$
c\left(4 I-b^{2}\right) F(z)=2 I \bar{F}(z)(a-c+z-\Lambda(z)) .
$$

Besides, the total profit of the centralized channel is

$$
\Pi_{c}\left(p_{c}^{*}(z), z, \theta_{c}^{*}(z)\right)=\frac{I(a-c+z-\Lambda(z))^{2}}{4 I-b^{2}}-c \Lambda(z) .
$$

By Eq. (3), it is easy to find that $p_{c}^{*}>c$.

Corollary 1:The stocking factor $z_{c}^{*}$ increases along with $a, b$, and decreases along with $c, I ; p_{c}^{*}$ and $\theta_{c}^{*}$ are all increasing along with $z$.

Market potential and consumer preferences for green products influence the inventory factor of the supply chain. The greater the market potential or the more consumers favor green products, the greater the inventory factor. Conversely, if the initial cost is higher, then the inventory factor is smaller. This can bring more profits. The retail

ISSN: 0010-8189 
price increases along with the increasing of inventory factor, and the enterprise needs to increase the green attributes of the product to obtain greater market competitiveness.

Corollary 2: The retail price $p_{c}^{*}$ increases along with parameters $a, b$, and decreases along with $I$; the greenlevel $\theta_{c}^{*}$ increases along with $a, b$, and decreases along with $c, I$; channel's total profit $\Pi_{c}^{*}$ increases along with $a$, $b$, and decreases along with $c, I$.

When market has greater potential or consumers prefer the green products, the enterprise should raise the price of green products, increase its green-level, expand the inventory, and then obtain greater returns. When there is less market potential or green products are not favored by the market, the enterprise should reduce the price, reduce its green-level, and reduce inventory.

\subsection{Research on Decentralized Channel}

Comparing to the 3.1, model in this part has competitiveness between two members. Each member decides his chosen in maximizing one's profit, giving no consideration to the other one. By game theory, the manufacturer firstly gives decision; the retailer secondly gives decision; the equilibrium decision will get thirdly.

Retailer: In case that the manufacturer has chosen $q, \omega, \theta$, we aim to obtain the optimal retail price. Since $q=z+y(p, \theta)$, we have

$$
\begin{aligned}
\Pi_{d, R}(p / z, \omega, \theta) & =(p-\omega) E[\min \{D, q\}] \\
& =(p-\omega) \Lambda(z)+(p-\omega)(z+a-p+b \theta)
\end{aligned}
$$

By first-order condition $\frac{\partial \Pi_{d, R}}{\partial p}=0$, then

$$
p_{d}(z, \omega, \theta)=\frac{a+b \theta+\omega+z-\Lambda(z)}{2} \text {. }
$$

This follows $\frac{\partial^{2} \Pi_{d, R}}{\partial p^{2}}=-2<0$, implying that Eq. (8) is the optimal decision.

Corollary 3: Retailer's retail price $p$ relies on and increases in $\omega, \theta, z$.

Manufacturer: Based on the retailer's selection of a certain retail price $p_{d}$, the manufacturer chooses his optimal decisions gradually to get the optimal solutions $z_{d}^{*}, \theta_{d}^{*}, \omega_{d}^{*}$. Then

$$
\begin{aligned}
\Pi_{d, M}(z, \omega, \theta / p) & =\omega E[\min \{D, q\}]-c q-I \theta^{2} \\
& =-\omega \Lambda(z)+(\omega-c)(z+a-p+b \theta)-I \theta^{2}
\end{aligned}
$$

Substituting Eq. (8) into Eq. (9), then

$$
\Pi_{d, M}(z, \omega, \theta / p)=-\omega \Lambda(z)+(\omega-c)\left(z+a+b \theta-\frac{\omega+a+b \theta+z-\Lambda(z)}{2}\right)-I \theta^{2}
$$

In the following theorem, our theorem describes the optimal decisions in the decentralized channel.

Theorem 2:In conditions $8 I-b^{2}>0$ and $h(z)>\frac{F(z) \bar{F}(z)}{a-c+z-\Lambda(z)}$, the decentralized supply chain has unique optimal decisions $\left(z_{d}^{*}, \omega_{d}^{*}, \theta_{d}^{*} / p_{d}^{*}\right)$ :

$$
p_{d}^{*}(z)=\frac{6 I(a-c+z-\Lambda(z))}{8 I-b^{2}}+c,
$$




$$
\begin{aligned}
& \omega_{d}^{*}(z)=\frac{4 I(a-c+z-\Lambda(z))}{8 I-b^{2}}+c,(12) \\
& \theta_{d}^{*}(z)=\frac{b(a-c+z-\Lambda(z))}{8 I-b^{2}},(13)
\end{aligned}
$$

and the optimal stocking factor $z=z_{d}^{*}$ is decided as

$$
c\left(8 I-b^{2}\right) F(z)=2 I \bar{F}(z)(a-c+z-\Lambda(z)) .(14)
$$

Besides, the profits of the manufacturer and the retailer are

$$
\Pi_{d, M}\left(z, \omega_{d}^{*}(z), \theta_{d}^{*}(z) / p_{d}^{*}(z)\right)=\frac{I(a-c+z-\Lambda(z))^{2}}{8 I-b^{2}}-c \Lambda(z),(15)
$$

and

$$
\Pi_{d, R}\left(p_{d}^{*}(z) / z, \omega_{d}^{*}(z), \theta_{d}^{*}(z)\right)=\frac{4 I^{2}(a-c+z-\Lambda(z))^{2}}{\left(8 I-b^{2}\right)^{2}} .(16)
$$

By Eqs. (11) and (12), the following corollary is reasonable to avoid the trival case.

Corollary4: In line with the market operation mode, there is, $p_{d}^{*}>\omega_{d}^{*}>c$.

By a similar calculation to Corollary2, we have the following results.

Corollary 5: The stocking factor $z_{d}^{*}$ increases along with $a, b$, and decreases along with $c, I ; p_{d}^{*}(z), \omega_{d}^{*}(z)$ and $\theta_{d}^{*}(z)$ are all increasing along with $z$.

Corollary 5 reveals that when the inventory factor is higher, the corresponding purchasing power is higher. This forces higher wholesale price and green-levelin earning more profit for the manufacturer. For the retailer, higher retail price will also performs well.

Corollary 6: $p_{d}^{*}, \omega_{d}^{*}$ increases along with parameters $a, b$, and decreases along with $I ; \theta_{d}^{*}(z)$ increases along with $a, b$, and decreases along with $c, I ; \Pi_{d, M}^{*}$ and $\Pi_{d, R}^{*}$ increases along with $a, b$, and decreases along with $c, I$.

The greater the market potential or the higher the consumer's preference for green products, the greater total profits of each member; of course, if production costs or green research and development investment costs increase, these will definitely reduce their profit.

Corollary 7: Comparison: $z_{d}^{*}<z_{c}^{*}, \theta_{d}^{*}<\theta_{c}^{*}$.

It is straightforward that the green-level reflects the protection to the environment. When two members in decentralized channel, they bargain for their own profit, leading to lower green-level. But in the centralized channel, all members are integrated as a whole unit, so the decision-maker can produce a higher green-level products, and is likely more efficient in environmental protection.

\section{Numerical Experiments}

ISSN: 0010-8189

(C) CONVERTER 2020

Www.converter-magazine.info 
In order to test and verify our models, we use hypothesis data sets to evaluate how the parameters influence on the optimal decisions and on the total profit. We consider the uniform distribution for the random variable $\varepsilon$ on [A,B], where $A=-50$ and $B=50$. Because the optimal decision mostly conscious to green investment and consumer demand. Therefore, we mainly study the influence of two parameters, $I$ and $b$, on the decision of green supply chain.

4.1 Numerical results as parameter $I$ changes

Before the simulations, according to the recent reference $\mathrm{Zhu}$ et $\mathrm{al}^{[24]}$, we set the important parameters as follows: $a=80, c=10, b=1.2, I \in[0.5,1]$.

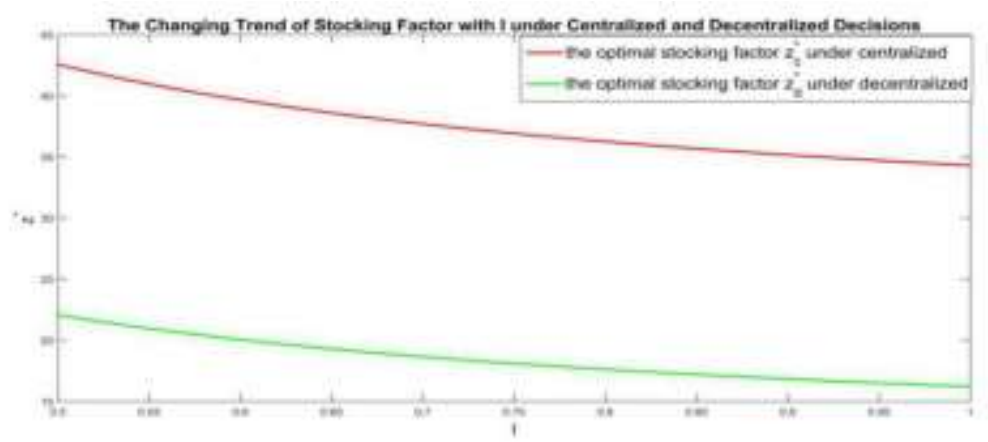

Figure2: The changing trend of stocking factor with I

Figure 2verifies that centralized decision-making reduces market competition and supply chain conflicts. Market is more active under supply chain cooperation. Manufacturers need to respond to market uncertainty through more inventory reserves to expand their maximum interests. In addition, both of them are decreasing in $I$, these implies that increasement of green investment reduces inventory factor, so as to offset negative effects of increased investment costs. This is consistent with the conclusions reached by Corollaries 1 and 5 .

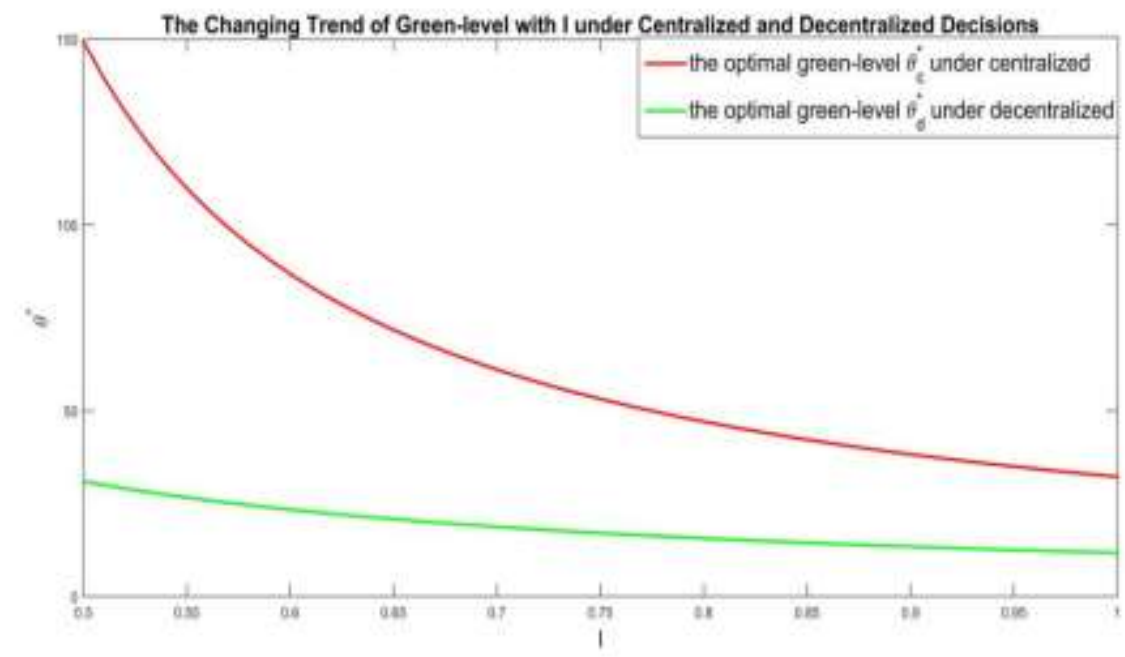

ISSN: 0010-8189 


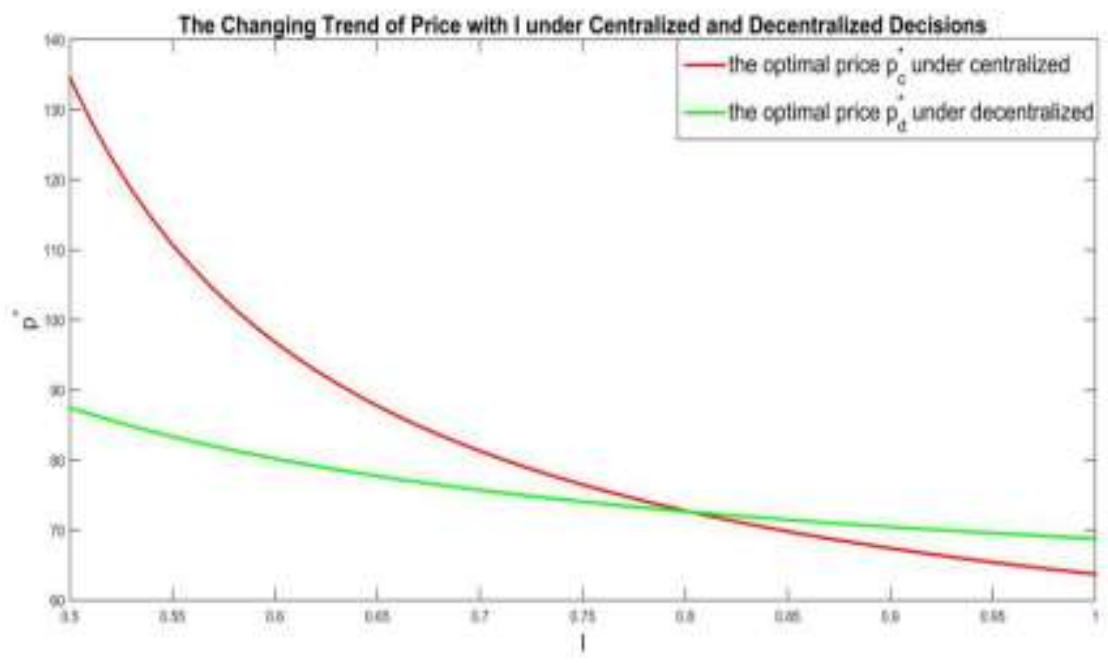

Figure3: The changing trend of green-level and retail price with I

Figure 3 verifies the property of green-level, implying that centralized channel works more conductive to green production of enterprises, and has a more active role in promoting investment in green product research and improving the environment. This is consistent with the conclusions reached by Corollaries 2 and 6 . Also we can see that the green-level in the centralized channel decreases sharply on $I$ than that in the decentralized case. Changes in green investment costs under centralized decision-making have a greater impact on product greenness. From the second graph in Figure 3, a very interesting phenomenon can be observed. When the green investment parameter is small, the retail price performs higher in centralized channel. When the green investment parameter is large, retail prices under decentralized decisions are higher than those under centralized decisions. This shows that Ihas a greater impact on retail prices under centralized decision making.

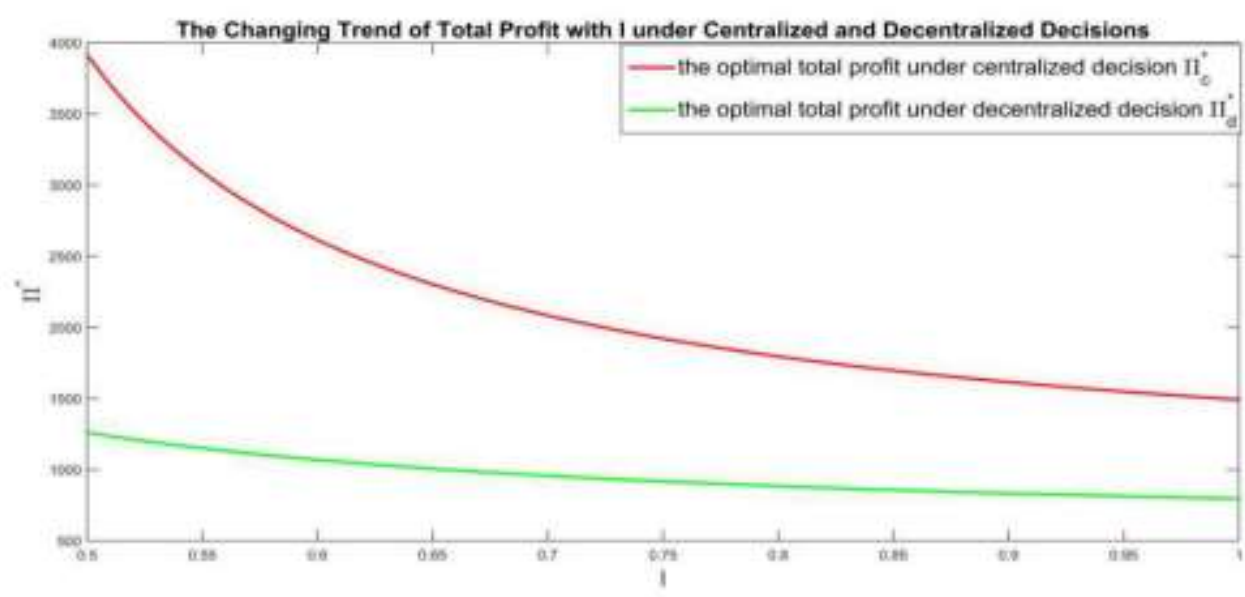

ISSN: 0010-8189 


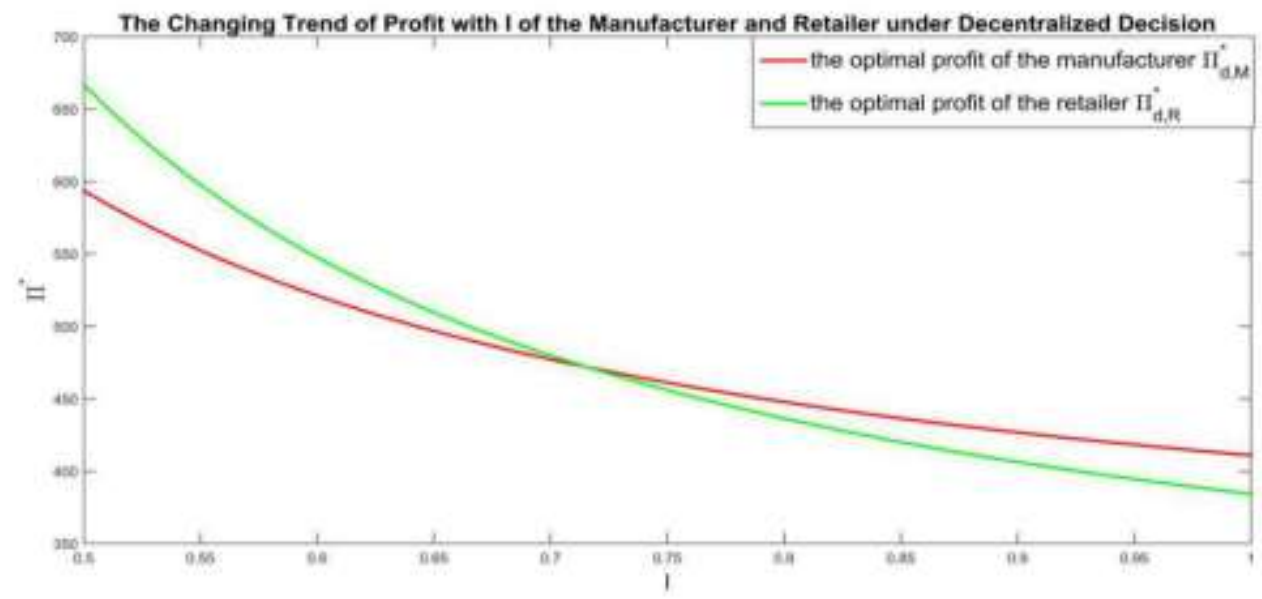

Figure4:The changing trend of total profit with I under centralized and decentralized decisions, and the changing trend of profit with I

From first figure of Figure 4, we see that centralized channel gets more profit. Both two channel's profits decreases in $I$, implying that when the green investment parameter increases, the channel's total profit will decrease. Profit in centralized channel is decreasing more sharply. Besides, from second figure of Figure 4, we see that two members' profits have intersection, which is not always fixed. Before the intersection, retailer gets more profit; after the intersection, manufacturer get more profit. Lower green investment parameters indicate that the green production technology is relatively mature. The maturity of the technology will bring more profits to the entire supply chain, but the retailer will benefit more from it. This may bring some difficulties to the research and development of green production technology.

\subsection{Numerical results as parameter $b$ changes}

We set the important parameters as follows: $a=80, c=10, I=0.58$, and $I \in[0.2,1.2]$.

Different from the decreasing trend of I in Figure 2, Figure 5 shows that the stocking factor in both two channels are increases along with $b$. This is consistent with the conclusions reached by our Corollaries 1 and 5 . A larger parameter $b$ indicates a stronger consumer preference and greater demand. Therefore, regardless of decentralized or centralized decision, the manufacturer will continuously expand the inventory factor as $b$ increases to deal with the risks caused by the uncertainty of demand. Moreover, the stocking factor in decentralized channel is always lower, and they have similar increasing trend.

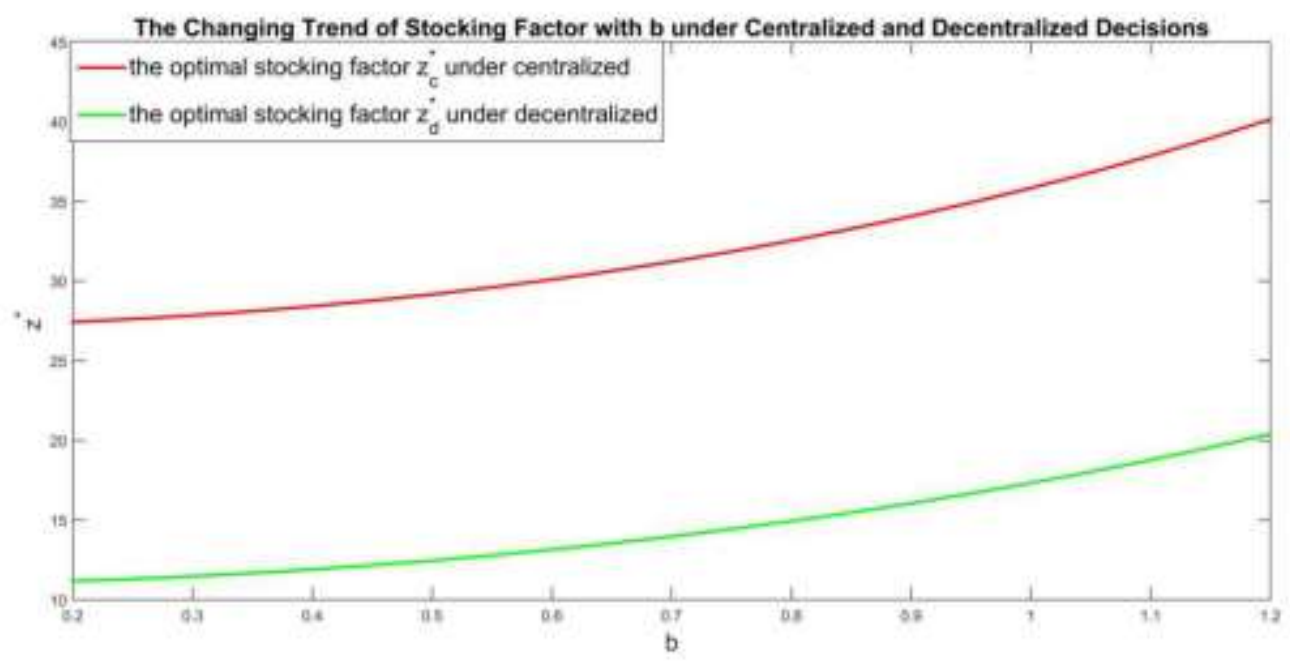

Figure5: The changing trend of stocking factor with $b$ under centralized and decentralized decisions ISSN: 0010-8189 
Figure 6 shows changes of green-level. It comes out that green-level incentralized channel increases more sharply. Retail price increases along with $\mathrm{b}$ both under decentralized and centralized decision-making. This is consistent with the conclusions reached by Corollaries 2 and 6 . The stronger consumers' preferences for green products, the manufacturer will increase investment in green R\&D after capturing this information, and increase green-level in satisfying consumer demand; besides, the retailer will also balance the market by increasing the retail price of products.
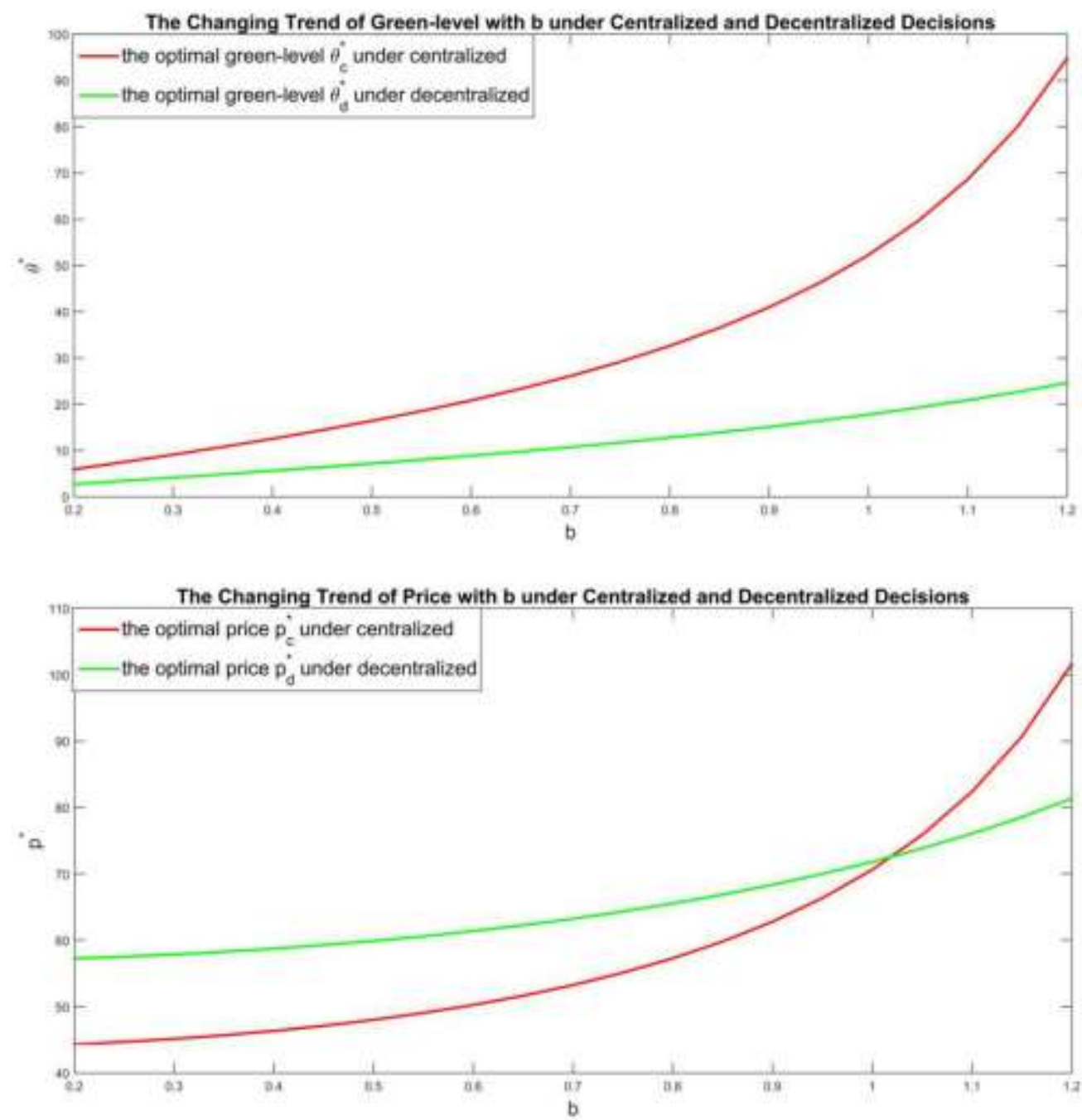

Figure 6: The changing trend of green-level and retail price with $b$

By second graph of Figure 6, when $\mathrm{b}$ is small, the retail price under decentralized channel performs higher; while when $b$ performs large enough, we have the conversely trend. This shows that impact of centralized decision prices on $b$ is more sensitive.

Figure 7 prohibits that total profit performs high when members acts as a unit. Both two channel's profit increases along with $b$, and the centralized case increases more sharply. Two members' profits have intersection, which is not always fixed. Before the intersection, manufacturer gets more profit; after the intersection, retailer gets more profit. The result shows reasonable, because retailer directly face consumers, and consumers' preferences for green products are directly affected by the retailer. The larger $b$, the larger the profit share that the retailer should get from the supply chain, due to the more efforts they put into promoting the product brand.

ISSN: 0010-8189 

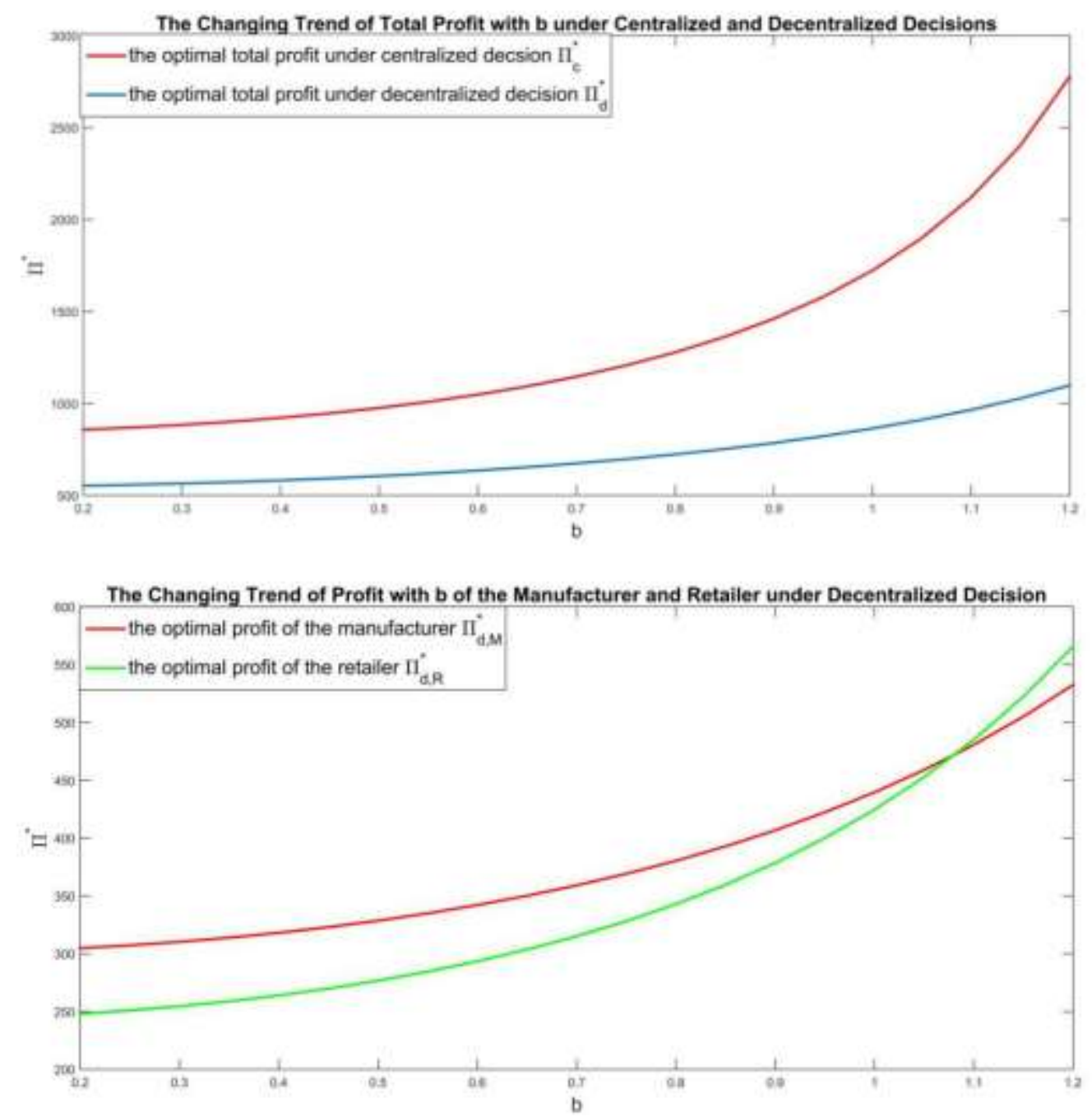

Figure 7: The changing trend of total profit with $b$ under centralized and decentralized decisions, and the changing trend of profit with $b$ of the manufacturer and the retailer under decentralized decision

\section{Conclusion}

Based on the linear random demand newsvendor model, we proposed a new model containing two members. In centralized supply chain, two members give their decisions together; in the decentralized channel, they bargain by game theory to get optimal decisions.

Results showed that cooperation between members can increase green-level and inventory factors due to random demand. Higher stocking factor leads to higher green-level and retail price. In addition, increasing market potential and increasing consumer preferences for green products will increase inventory factors and sales prices, thereby increase profits of the supply chain. Larger production costs or green investments will reduce inventory factors and sales prices, and reduce total channel's profit. This suggests: strengthening promotion of green products, enhancing green production technology, and increasing consumers' awareness of environmental protection, are all helpful to entire channel. Profit distribution will be affected by various parameters. Through numerical calculations, profit sharing ratio of manufacturer increases in $I$ and decreases in $b$. It can also be seen from this that the retailer will receive relatively more returns from improvements in green production technology and consumer preferences for green products. For practitioners, our model provides theoretical basis and practical guidance for production decision-making in green supply chains under uncertain demand.

\section{Appendix}

ISSN: 0010-8189 
Proof of Theorem 1: By Eq. (2), we have

$$
\frac{\partial \Pi_{c}(p, z, \theta)}{\partial p}=(z+a-p+b \theta)-(p-c)-\Lambda(z)=0
$$

and hence

$$
p_{c}^{*}(\theta, z)=\frac{a+c+b \theta+z-\Lambda(z)}{2}
$$

By Eq. (17), Eq. (2), reduces to

$$
\Pi_{c}\left(p_{c}^{*}(\theta, z), z, \theta\right)=\frac{1}{4}(a+b \theta-c+z-\Lambda(z))^{2}-c \Lambda(z)-I \theta^{2}
$$

The optimal $\theta_{\mathrm{c}}^{*}$ satisfies the first-order condition of

$$
\frac{\partial \Pi_{c}(p, z, \theta)}{\partial \theta}=\frac{b}{2}(a+b \theta-c+z-\Lambda(z))-2 I \theta=0
$$

And this gives us Eq. (4). Substituting Eq. (4) into Eq. (17), we have

$$
p_{c}^{*}(z)=\frac{2 I(a-c+z-\Lambda(z))}{4 I-b^{2}}+c
$$

That is Eq. (3); and substituting Eq. (4) into Eq. (18), the profit function can then be reduced to

$$
\Pi_{c}\left(p_{c}^{*}(z), z, \theta_{c}^{*}(z)\right)=\frac{f(a-c+z-\Lambda(z))^{2}}{4 I-b^{2}}-c \Lambda(z)
$$

Similarly, first-order condition requires the optimal $\mathrm{z}_{\mathrm{c}}^{*}$ satisfying

$$
\frac{d \Pi_{c}\left(p_{c}^{*}(z), z, \theta_{c}^{*}(z)\right)}{d z}=0
$$

And this gives us Eq. (5). To verify the uniqueness ofz $\mathrm{c}_{c}^{*}$, we only need to show $\frac{d^{2} \Pi_{c}\left(p_{c}^{*}(z), z, \theta_{c}^{*}(z)\right)}{d z^{2}}<0$ in the case of $\frac{d \Pi_{c}\left(p_{c}^{*}(z), z, \theta_{c}^{*}(z)\right)}{d z}=0$. Note that

$$
\frac{d^{2} \Pi_{c}\left(p_{c}^{*}(z), z, \theta_{c}^{*}(z)\right)}{d z^{2}}=\frac{2 I}{4 I-b^{2}} \bar{F}(z)^{2}+\frac{2 I}{4 I-b^{2}}(a-c+z-\Lambda(z))(-f(z))-c f(z)
$$

By Eq. (5), we have $\frac{2 I}{4 I-b^{2}}(a-c+z-\Lambda(z))=\frac{c F(z)}{\bar{F}(z)}$. Thus, $\frac{d^{2} \Pi_{c}\left(p_{c}^{*}(z), z, \theta_{c}^{*}(z)\right)}{d z^{2}}=\frac{c F(z) \bar{F}(z)^{2}-c f(z)(a-c+z-\Lambda(z))}{(a-c+z-\Lambda(z)) \bar{F}(z)}$.

Since $a-c+z-\Lambda(z)>0$

$$
\frac{d^{2} \Pi_{c}\left(p_{c}^{*}(z), z, \theta_{c}^{*}(z)\right)}{d z^{2}}<0
$$

Proof of Corollary 1: By Eq. (5), we denote $M(z)=2 I f(z)(a-c+z-\Lambda(z))+c\left(4 I-b^{2}\right) f(z)-2 I \bar{F}(z)^{2}$. Then 


$$
\begin{aligned}
M(z) & =2 I f(z)(a-c+z-\Lambda(z))+\frac{2 I \bar{F}(z)(a-c+z-\Lambda(z))}{F(z)} f(z)-2 I \bar{F}(z)^{2} \\
& =2 I \frac{f(z)(a-c+z-\Lambda(z))}{F(z)}-2 I \bar{F}(z)^{2}
\end{aligned}
$$

By our condition that $h(z)>\frac{F(z) \bar{F}(z)}{a-c+z-\Lambda(z)}$, Eq.(20) simplified as

$$
M(z)>0 .(21)
$$

Now we are ready to prove the increasing properties of $z=z_{c}^{*}$ on $a$ and $b$, and decreasing properties on $c$ and $I$. By Eq. (5), we have

$$
\begin{aligned}
& \frac{d z(a)}{d a}=\frac{2 I \bar{F}(z)}{M(z)}>0 \\
& \frac{d z(b)}{d b}=\frac{2 b c F(z)}{M(z)}>0 \\
& \frac{d z(c)}{d c}=\frac{2 I \bar{F}(z)+\left(4 I-b^{2}\right) F(z)}{-M(z)}<0
\end{aligned}
$$

This implies that $z$ increases along with $a, b$, and decreases along with $c$. Next,

$$
\frac{d z(I)}{d I}=\frac{4 c F(z)-2 \bar{F}(z)(a-c+z-\Lambda(z))}{-M(z)}
$$

Substituting Eq. (5) into Eq. (23), we have

$$
\frac{d z(I)}{d I}=\frac{b^{2} c F(z)}{-I M(z)}<0
$$

This implies that $z$ is decreasing in $I$. One can easily prove the increasing property of $p_{c}^{*}$ and $\theta_{c}^{*}$ in $z$.

Proof of Corollary 2: By Eq. (3), we have

$$
\frac{d p_{c}^{*}(a)}{d a}=\frac{2 I\left[1+\bar{F}(z) \frac{d z}{d a}\right]}{4 I-b^{2}} .
$$

By Corollary 1, we have $\frac{d z}{d a}>0$ and hence $\frac{d p_{c}^{*}}{d a}>0$. This shows that $p_{c}^{*}$ is increasing in $a$.

To simplify our calculation of the deviations on $b$ and $I$, we have the following equation by multiplying $4 I-b^{2}$ of Eq. (3)

$$
p_{c}^{*}\left(4 I-b^{2}\right)=2 I(a-c+z-\Lambda(z))+c\left(4 I-b^{2}\right)
$$

By the first-order condition, we have

$$
\frac{d p_{c}^{*}(b)}{d b}=\frac{2 I \bar{F}(z) \frac{d z}{d b}+2 b\left(p_{c}^{*}-c\right)}{4 I-b^{2}}
$$

By Corollary1, we have $\frac{d z}{d b}>0$ and $p_{c}^{*}>c$, and hence $\frac{d p_{c}^{*}}{d b}>0$.

Similarly,

ISSN: 0010-8189

C CONVERTER 2020 


$$
\begin{aligned}
\frac{d p_{c}^{*}(I)}{d I} & =\frac{2(a-c+z-\Lambda(z))+2 I \bar{F}(z) \frac{d z}{d I}+4(c-p)}{4 I-b^{2}} \\
& =\frac{2(a-c+z-\Lambda(z))+2 I \bar{F}(z) \frac{d z}{d I}+4\left[-\frac{2 I(a-c+z-\Lambda(z))}{4 I-b^{2}}\right]}{4 I-b^{2}} \\
& =\frac{(a-c+z-\Lambda(z))\left[2-\frac{8 I}{4 I-b^{2}}\right]+2 I \bar{F}(z) \frac{d z}{d I}}{4 I-b^{2}} \\
& =\frac{-2 b^{2}(a-c+z-\Lambda(z))+2 I\left(4 I-b^{2}\right) \bar{F}(z) \frac{d z}{d I}}{\left(4 I-b^{2}\right)^{2}}
\end{aligned}
$$

By corollary 1 , we have $\frac{\mathrm{dz}}{\mathrm{dI}}<0$ and hence $\frac{\mathrm{dp}_{\mathrm{c}}^{*}}{\mathrm{dI}}<0$.

By Eq. (4), we have

$$
\frac{d \theta_{c}^{*}(a)}{d a}=\frac{b\left(1+\bar{F}(z) \frac{d z}{d a}\right)}{4 I-b^{2}}
$$

And

$$
\frac{d \theta_{c}^{*}(c)}{d c}=\frac{b\left(-1+\bar{F}(z) \frac{d z}{d c}\right)}{4 I-b^{2}}
$$

By Corollary 1 , we have $\frac{\mathrm{dz}}{\mathrm{dI}}>0$ and $\frac{\mathrm{dz}}{\mathrm{dI}}<0$, and this implies that $\frac{\mathrm{d} \theta_{\mathrm{c}}^{*}}{\mathrm{ab}}>0$ and $\frac{\mathrm{d} \theta_{\mathrm{c}}^{*}}{\mathrm{dI}}<0$.

Now, we are ready to find the deviations of $\theta_{c}^{*}$ on $b$ and $I$. By multiplying $4 I-b^{2}$ on Eq. (4), we have

$$
\left(4 I-b^{2}\right) \theta_{c}^{*}=b(a-c+z-\Lambda(z)) \text {. }
$$

It follows that

$$
\begin{aligned}
& \frac{d \theta_{c}^{*}(b)}{d b}=\frac{(a-c+z-\Lambda(z))+2 b \theta+b \bar{F}(z) \frac{d z}{d b}}{4 I-b^{2}} \\
& \frac{d \theta_{c}^{*}(I)}{d I}=\frac{b \bar{F}(z) \frac{d z}{d I}-4 \theta}{4 I-b^{2}} .
\end{aligned}
$$

By corollary 1, we have $\frac{d z}{d I}>0$ and $\frac{d z}{d I}<0$, and this follows $\frac{d \theta_{c}^{*}}{d l}>0$ and $\frac{d \theta_{c}^{*}}{d I}<0$.

By Eq. (6), we have

And

$$
\begin{aligned}
\frac{d \Pi_{c}^{*}(a)}{d a} & =\frac{2 I(a-c+z-\Lambda(z))\left(1+\bar{F}(z) \frac{d z}{d a}\right)}{4 I-b^{2}}-c F(z) \frac{d z}{d a} \\
& =\frac{c F(z)}{\bar{F}(z)}\left(1+\bar{F}(z) \frac{d z}{d a}\right)-c F(z) \frac{d z}{d a} \\
& =\frac{c F(z)}{\bar{F}(z)}>0
\end{aligned}
$$

ISSN: 0010-8189 
This implies that the total profit $\Pi_{c}^{*}$ is increasing in $a$, and decreasing in $c$. By multiplying $4 I-b^{2}$ on Eq. (6), we have

$$
\left(4 I-b^{2}\right) \Pi_{c}^{*}=I(a-c+z-\Lambda(z))^{2}-c \Lambda(z)\left(4 I-b^{2}\right) .
$$

By the first-order condition, we have

$$
\begin{aligned}
\frac{d \Pi_{c}^{*}(b)}{d b} & =\frac{2 I(a-c+z-\Lambda(z)) \bar{F}(z) \frac{d z}{d b}-c\left(4 I-b^{2}\right) \bar{F}(z) \frac{d z}{d b}+2 b\left(\Pi_{c}^{*}+c \Lambda(z)\right)}{4 I-b^{2}} \\
& =\frac{c\left(4 I-b^{2}\right) F(z) \frac{d z}{d b}-c\left(4 I-b^{2}\right) \bar{F}(z) \frac{d z}{d b}+2 b\left(\Pi_{c}^{*}+c \Lambda(z)\right)}{4 I-b^{2}} \\
& =\frac{2 b\left(\Pi_{c}^{*}+c \Lambda(z)\right)}{4 I-b^{2}}>0
\end{aligned}
$$

And

$$
\frac{d \Pi_{c}^{*}(I)}{d I}=\frac{-b^{2}}{4 I-b^{2}}(a-c+z-\Lambda(z))^{2}<0
$$

This follows that the total profit $\Pi_{c}^{*}$ is increasing in $b$, and decreasing in $I$.

Proof of Corollary 3: This can be checked by using the first-order condition.

Proof of Theorem 2: By Eq. (10),

$$
\frac{\partial \Pi_{d, M}}{\partial \omega}=-\Lambda(z)+\left(z+a+b \theta-\frac{\omega+a+b \theta+z-\Lambda(z)}{2}\right)+(\omega-c)\left(-\frac{1}{2}\right)=0
$$

And

$$
\frac{\partial \Pi_{d, M}}{\partial \theta}=(\omega-c)\left(b-\frac{b}{2}\right)-2 I \theta=0 .
$$

It follows that

$$
\omega=\frac{a+b \theta+c+z-\Lambda(z)}{2}
$$

And

$$
\theta=\frac{b(\omega-c)}{4 I}
$$

By combining the two equations we can get $\omega_{d}^{*}(z)$ and $\theta_{d}^{*}(z)$, that is, Eqs. (12) and (13). Substituting Eqs. (12) and (13) into Eq. (8), we have Eq. (11). Now, substituting Eqs. (11)-(13) into Eq. (10), we have

$$
\Pi_{d, M}\left(z, \omega_{d}^{*}(z), \frac{\theta_{d}^{*}(z)}{p_{d}^{*}(z)}\right)=\frac{I(a-c+z-\Lambda(z))^{2}}{8 I-b^{2}}-c \Lambda(z)
$$

After this, substituting Eqs. (11)-(13) into Eq. (7), we have

$$
\Pi_{d, R}\left(\frac{p_{d}^{*}(z)}{z}, \omega_{d}^{*}(z), \theta_{d}^{*}(z)\right)=\frac{4 I^{2}(a-c+z-\Lambda(z))^{2}}{\left(8 I-b^{2}\right)^{2}}
$$

Also, by the first-order condition, we get $\frac{d \Pi_{d, M}\left(z, \omega_{d}^{*}(z), \frac{\theta_{d}^{*}(z)}{p_{d}^{*}(z)}\right)}{d z}=\frac{2 I(a-c+z-\Lambda(z)) \bar{F}(z)}{8 I-b^{2}}-c F(z)=0$, andthis gives us Eq. (14). Except changing $4 I-b^{2}$ to $8 I-b^{2}$, the process of proving the uniqueness of $z_{d}^{*}$ is exactly the same as in Theorem 1.

Proof of Corollary 8: Recall that both $z_{c}^{*}$ and $z_{d}^{*}$ satisfy the Eqs. (5) and (14) respectively. Let $G(z)=$ 
$(a-c+z-\Lambda(z)) \frac{\bar{F}(z)}{F(z)}$. By our assumption, we have

$$
\frac{d G(z)}{d z}=\frac{F(z) \bar{F}(z)^{2}-f(z)(a-c+z-\Lambda(z))}{F^{2}(z)}<0
$$

Then $G(z)$ is decreasing on $[A, B]$. Since $G\left(z_{d}^{*}\right)=\frac{c\left(8 I-b^{2}\right)}{2 I}>\frac{c\left(4 I-b^{2}\right)}{2 I}=G\left(z_{c}^{*}\right)$. Since, we have $z_{d}^{*}<z_{c}^{*}$.

Since $a-c+z-\Lambda(z)$ is increasing on $[A, B]$ and $z_{d}^{*}<z_{c}^{*}$, we have $a-c+z_{d}^{*}-\Lambda\left(z_{d}^{*}\right)<a-c+z_{c}^{*}-\Lambda\left(z_{c}^{*}\right)$; and since $0<4 I-b^{2}<8 I-b^{2}$, we have that $\theta_{d}^{*}=\frac{b\left(a-c+z_{d}^{*}-\Lambda\left(z_{d}^{*}\right)\right)}{8 I-b^{2}}<\frac{b\left(a-c+z_{c}^{*}-\Lambda\left(z_{c}^{*}\right)\right)}{4 I-b^{2}}=\theta_{c}^{*}$. By Eqs (4) and (13), we have $\theta_{d}^{*}<\theta_{c}^{*}$.

\section{Acknowledgements:}

This research was supported by National Natural Science Foundation of China (Grant No. 72002029), and the Tianjin Municipal Education Commission (Grant No. 2018KJ229).

\section{References}

[1] Q. Zhu,J. Sarkis, K.H. Lai, "Institutional-based antecedents and performance outcomes of internal and external green supply chain management practices," Journal of Purchasing and Supply Management,vol.19, pp. 106-117, 2013.

[2] J. Jayaram, B. Avittathur, "Green supply chains: a perspective from an emerging economy," International Journal of Production Economics, vol. 164, pp. 234-244, 2015.

[3] R.B. Handfield, S.V. Walton, "Green supply chain: Best practices from the furniture industry," Proceedings, Annual Meeting of the Decision Science Institute USA, vol. 3, pp. 1295-1297, 1996.

[4] S.G. Lee, B.K. Kim,"The effects of internal green supply chain management on the external green supply chain management and environmental performance," Journal of Korean Society of Supply Chain Management, vol. 17, pp. 67-76, 2017.

[5] D. Ghosh, J. Shah, "A comparative analysis of greening policies across supply chain structures," International Journal of Production Economics, vol. 212, pp. 568-583, 2012.

[6] Y.C. Dai, "Haier starts green strategy," South Daily, 2011.11.24.

[7] Y. Yu, X. Han, G. Hu, "Optimal production for manufacturers considering consumer environmental awareness and green subsidies," International Journal of Production Economics, vol. 182, pp. 397-408, 2016.

[8] F. Wang, X.F. Lai, N. Shi, "A multi-objective optimization for greensupply chain network design," Decision Supports Systems, vol. 51, no. 2, pp. 262-269, 2011.

[9] L.Ameknassi, D. Ait-Kadi, N. Rezg, "Integration of logistics outsourcingdecisions in a green supply chain design: A stochastic multi-objective multi-periodmulti-product programming model," International Journal of Production Economics,vol. 182, pp. 165-184, 2016.

[10] K.P. Nurjanni, M.S. Carvalho, L. Costa, Green supply chain design: A mathematical modeling approach based on a multi-objective optimization model," International Journal of Production Economics,vol. 183,pp. 421-432, 2017.

[11] C. Waltho, S. Elhedhli, F. Gzara, "Green supply chain network design: A review focused on policy adoption and emission quantification," International Journal of Production Economics, vol. 208, pp. 305-318, 2019.

[12] Z. Ghelichi, M. Saidi-Mehrabad, M.S. Pishvaee, "A stochastic programming approach toward optimal design and planning of an integrated green biodiesel supply chain network under uncertainty: A case study," Energy,vol. 156, pp. 661-687, 2018.

[13] S.O. Bhakti, P. Javier, G.C. Canan, A.J. Angel, "Agri-food supply chains with stochastic demands: A multi-period inventory routing problem with perishable products," Simulation Modelling Practice and Theory, https://doi.org/10.1016/j.simpat.2019.101970, 2019.

ISSN: 0010-8189 
[14] M. Yu, J.N. Zhang, "Equilibrium in production chains with multiple upstream partners," Journal of Mathematical Economics,vol. 83, pp. 1-10, 2019.

[15] T. Islam, A. Azeem, M. Jabir, A. Paul, S.K. Paul, “An inventory model for a three-stage supply chain with random capacities considering disruptions and supplier reliability," Annal of Operations Research, DOI: $10.1007 / \mathrm{s} 10479-020-03639-\mathrm{z}, 2020$.

[16] C. Xin, X. Chen, H.F. Chen, S.R. Chen, M.Q. Zhang, "Green product supply chain coordination under demand uncertainty,” IEEE Access, vol. 8, pp. 25877-25891, 2020.

[17] S. Badi, N. Murtagh, "Green supply chain management in construction: A systematic literature review and future research agenda," Journal of Cleaner Production, vol. 223, pp. 312-322, 2019.

[18] G. Tsoulfas, C. Pappis, "Environmental principles applicable to supply chains design and operation," Journal of Cleaner Production, vol. 14, pp. 1593-1602, 2006.

[19] W.G. Zhu, Y.J. He, S.L. Zhao, "Green product design in supply chains under competation," European Journal of Operational Research, vol. 258, pp. 165-180, 2017.

[20] J.Z. Wang, L. Jiang, Z.J. Shen, "Channel performance under consignment contract with revenue sharing," Management Science, vol. 50, no. 1, pp. 34-47, 2004.

[21] S.J. Li, Z.B. Zhu, L.H. Huang, "Supply chain coordination and decision making under consignment contract with revenue sharing," International Journal of Production Economics, vol. 120, pp. 88-99, 2009.

[22] N.C. Petruzzi, M. Dada, "Pricing and the newsvendor problem: A review with extensions," Operations Research, vol. 47, no. 2, pp. 183-194, 1999.

[23] T.M. Choi, T.C.E. Cheng, "Supply chain coordination under uncertainty," Springer, Berlin, Heidelberg, 2011.

[24] Q.H. Zhu, X.Y. Li, S.L. Zhao, "Cost-sharing models for green product production and marketing in a food supply chain,” Industrial Management \& Data Systems, vol. 118, no. 4, pp. 654-682, 2018. 